\section{Mucins in Histopathology}

\section{ACP Course: Wednesday, 24 May 1989 \\ Department of Pathology, University of Leeds}

Programme includes: Mucus glycoproteins-structural/functional relationships and biochemical/histochemical correlations. Critical review of histochemical techniques for the demonstration of epithelial glycoproteins. Lectins: structure, functions, and uses. Mucins in the gastrointestinal tract. Mucins in the respiratory tract. Mucins in the genitourinary tract. Mucins in the breast. Mucus antigens and cancer.

Course Fee: $£ 25.00$ (to include refreshments and lunch)

Apply to Dr M Wells, Department of Pathology, University of Leeds, Leeds LS2 9JT.

\section{National Heart and Lung Institute}

\section{Course in Lung Pathology 12-15 June 1989}

A course of lectures, hands-on microscopy sessions, and a slide seminar will be held at the National Heart and Lung Institute, Brompton Hospital, London.

Lecturers will include: B J Addis, P J Cole, B Corrin, P da Costa, B Fox, A R Gills, M Griffiths, P K Jeffery, M N Sheppard, S Stewart and C A Wagenvoort.

Programme and application forms available from: Postgraduate Centre, National Heart and Lung Institute, Dovehouse Street, London SW3 6LY. (01) 3518172.

\section{Fourth Annual Meeting Clinical Applications of Cytometry

\author{
Charleston, South Carolina, USA \\ September 13-16, 1989
}

Four symposia will cover the topics: transplantation; image analysis; quantitation of immunofluorescence and intracellular probing; and leukaemia/lymphoma immunophenotyping.

Related poster sessions and workshops will also be held.

For detailed information regarding the programme, advance registration, and submission of abstracts write to: Mariano La Via, Clinical Applications of Cytometry, P.O. Box 39778, Charleston, South Carolina 29407, USA.

\section{External Quality Assessment in Histopathology and Cytopathology}

External Quality Assessment is of increasing importance in histopathology and cytology. With the advent of the cytology proficiency testing scheme and the need to control quality of the newly implemented breast cancer screening, the Royal College of Pathologists and the Association of Clinical Pathologists are presenting a special one day symposium at St Bartholomew's Hospital, London EC1, on Monday April 24, 1989. Fee $£ 40.00$ including buffet lunch.

Further details from: Professor G Slavin, Department of Histopathology, St Bartholomew's Hospital, West Smithfield, London EC1.

\section{ACP Locum Bureau}

The Association of Clinical Pathologists runs a locum bureau for consultant pathologists.

Applicants with the MRC Path who would like to do locums and anyone requiring a locum should contact $\mathrm{Dr}$ DH Orrell, Department of Pathology, Royal Lancaster Infirmary, Ashton Road, Lancaster LA1 4RP.

\section{Corrections}

The references to the paper by Burns, Graham, and McGee were incorrect at time of press (J Clin Pathol 1988;41:897-99) and should be as follows:

\section{References}

1 Burns J, Graham AK, Frank C, Fleming KA, Evans MP, McGee JO'D. Detection of low copy human papilloma virus DNA and mRNA in routine paraffin sections of cervix by non isotopic in situ hybridization. J Clin Pathol 1987;40:858-64.

2 Syr Jonen S, Syr Jonen K. An improved in situ DHA hybridization protocol for detection of human papillomovirus (HPV) DNA sequences in paraffin-embedded biopsies. $J$ Virol Methods 1986;14:293-304.

3 Ferguson DJP, Harrison D, Burns J, Jonasson JA, McGee JO'D. Chromosomal localization of genes by scanning electron microscopy using in situ hybridization with biotinylated probes: $\mathrm{Y}$ chromosome repetitive sequences. Histochem J 1986;18:266-70.

4 Henke R-P, Milde-Lengosch K, Loning T, Kopping HS. Human papillomovirus type 13 and local epithelial hyperplasia of the oral mucosa: DNA hybridization on paraffinembedded specimens. Virchows Arch A 1987;411:193-8.

5 Chan VT-W, Fleming KA, McGee JO'D. Detection of subpicogram quantities of specific DNA sequences on blot hybridization with biotinylated probes. Nucleic Acids Res 1985;13:8083-91.

An error was inadvertently made to the title of the paper by Dr Savltzipori (J Clin Pathol 1988;41:1099-103). It should have read: Cerebral involvement associated with Escherichia coli 0157: H7 in humans and gnotobiotic piglets.

Broadsheet 120, January 1989: Folio 7 of the above broadsheet: (Guide to Diagnosis of inborn errors of metabolism in district general hospitals, has been reprinted owing to a series of printing errors (enclosed with this issue). 
increase may be intermittent or exacerbated by a carbohydrate meal or by exercise. A chronic increase of plasma lactate concentration may be associated with increased plasma and urine alanine, plasma proline, and urate concentrations. Plasma pyruvate is usually increased but does not aid differential diagnosis.

Increased urinary lactate only occurs if the renal threshold (about $7.0 \mathrm{mmol} / \mathrm{l}$ ) is exceeded. Further investigation of a clinically important lactic acidosis includes fasting glucose, urine and plasma amino acids, and urine organic acids.

\section{AMMONIA}

Plasma ammonia in healthy adults and children (1 month to 14 years) is less than $40 \mu \mathrm{mol} / 1$ and is not affected by fasting. Healthy term infants in the first few days of life may have concentrations up to 100 $\mu \mathrm{mol} / \mathrm{l}$. In preterm infants and sick neonates concentrations may reach $200 \mu \mathrm{mol} / 1$. Hyperammonaemia is not a diagnosis and requires further biochemical investigation. ${ }^{14}$

\section{URINARY METHYLMALONIC ACID}

Excess urinary methylmalonic acid occurs as a result of cobalamin deficiency (including a vegan diet) or one of the several inherited defects of methylmalonic acid metabolism. The finding of methylmalonic aciduria together with homocystinuria occurs in some of the cobalamin metabolic defects. This is a complex area and the finding of methylmalonic acid in the urine must be fully investigated.

\section{URINARY SUGARS}

Clinically important galactosuria-that is, greater than $2 \mathrm{~g} / 100 \mathrm{ml}$-in a neonate suggests galactosaemia, but may also occur in patients with other causes of liver disease-for example, tyrosinaemia type I. The baby should be taken off lactose immediately while further investigations (particularly erythrocyte galactose-l-phosphate uridyl transferase and urine/plasma amino acids) are undertaken.

In older children without liver disease galactosuria suggests the possibility of galactokinase deficiency. Fructosuria requires investigation for the possibility of fructose intolerance or fructosaemia.

Beware of xylose following tolerance tests. Several minor bands - for example, lactulose, raffinose-can result from dietary sources. Heavily staining bands at or near the origin require further investigation of urinary oligosaccharides as they may indicate mucoli pidoses or possible glycogen storage disease.

More detailed interpretation of these tests and a guide to further investigations is beyond the scope of this paper, and advice from a specialist centre must be sought.

\section{Appendix}

GUIDE FOR EMERGENCY SPECIMEN COLLECTION In life-threatening situations, where an inherited metabolic disorder is thought to be likely (either from family history, results of preliminary investigations, or clinical presentation), the following specimens should be taken. At the earliest opportunity contact a specialist laboratory to discuss appropriate investigations. If possible, urine and blood specimens should be taken before death. Skin and tissue specimens should be taken as soon as possible after death.

If any of the samples are taken after death it is extremely important to record accurately both the time of death and when the samples were taken. Appropriate storage as detailed below is essential.

\section{Urine}

Ideally at least $10 \mathrm{ml}$ of random urine. Collect into a bottle with no preservative and store deep frozen $\left(-20^{\circ} \mathrm{C}\right.$ or lower). If the sample is contaminated with blood centrifuge to remove cells before freezing supernatant.

\section{Blood}

Collect $10 \mathrm{ml}$ of heparinised blood, separate plasma as soon as possible and store plasma deepfrozen $\left(-20^{\circ} \mathrm{C}\right)$. Store the packed red cells at $+4^{\circ} \mathrm{C}$ (do not freeze). If DNA analysis is likely to be required, store a further $10 \mathrm{ml}$ whole blood (edetic acid) in a plastic tube deep frozen (at least $-20^{\circ} \mathrm{C}$ ).

3 Skin (for fibroblast culture)

Skin taken up to 24 hours after death is likely to be viable provided it is not infected. Take a skin sample and place it in suitable transport medium* (obtainable from most virology or cytogenetics departments). In an emergency sterile isotonic saline can be used, but do not use agar. The specimen should be stored at $+4^{\circ} \mathrm{C}$ before despatch. Do not freeze.

Sterility is of paramount importance when taking skin biopsy specimens, especially at necropsy.

If indicated:

4 Tissue samples (liver, heart muscle, skeletal muscle) These should only be taken if there is a strong clinical suspicion of a primary defect in one of these tissues. It is very important that blood and urine specimens are also taken and not just tissue specimens. Necropsy tissue samples are only suitable for biochemical analysis if taken within two hours of death. Two or three needle biopsy specimens of tissue should be taken, wrapped in aluminium foil, and snap frozen in liquid nitrogen (or solid $\mathrm{Co}_{2}$ ). Store the sample deep frozen, as cold as possible. 